\title{
O PAPEL DA EDUCAÇÃO SANITĀRIA NA PROFILAXIA DO TRACOMA *
}

\author{
Netson L. de A. Moraes* \\ Orlando José da Sulva ** \\ Joaquim de Arruda Camargo *** \\ José Péricles freire
}

É unânime a opinião dos autores quanto ao importante papel da educação sanitária no combate ao tracoma.

O primeiro relatório da Comissão de Peritos do Tracoma ${ }^{4}$ diz, mesmo, a êsse respeito:

"A Comissão considera que a educação sanitária é de importância capital na profiláxia da doença, e que ela deve ser desenvolvida na maior escala possivel, por todos os meios disponíveis e através das modernas técnicas de propaganda, adaptadas às condições locais. Deve ser despertado o interêsse das professoras, das quais é preciso obter intima colaboração."

"O objetivo deve ser a criação de um senso de responsabilidade coletiva e individual, com relação ao contrôle do tracoma."

"Os ensinamentos devem dar destaque aos perigos e sérias consequências - individuais e familiares, sociais e nacionais - da doença; deven estimular o doente a procurar tratamento, para si e sua família, mostrando que tal tratamento acha-se disponível e é eficiente."

No presente trabalho, desejamos fazer um estudo crítico dos conselhos ou ensinamentos habitualmente ministrados no Brasil, no sentido de evitar a transmissão da doença, e das técnicas de propaganda utilizadas em sua

Encaminhado para publicação em dezembro de 1953.

Trabalho apresentado ao $11^{\circ}$. Congresso Brasileiro de Higiene. Curitiba, 1953.

* Docente livre e assistente da Cadeira de Epidemiologia e Profilaxia Gerais e Especiais (Prof. A. L. Ayrosa Galvão) da Faculdade de Higiene e Saúde Pública da Universidade de São Paulo.

* Diretor da Divisão de Eảucação e Treinamento do SESP.

** Médico do Serviço Especial de Saúde em Araraquara.

*** Diretor do Serviço Especial de Saúde em Araraquara. 
divulgação, apresentando, a seguir, os princípios gerais que, em nossa opinião, devem nortear a campanha de educação sanitária para o combate ao tracoma.

Visaremos sobretudo a zona rural, onde é particularmente difícil o trabalho profilático.

Para facilidade de exposição, dividiremos os conselhos ou ensinamentos usados para a profilaxia do tracoma nos seguintes grupos:

I) Asseio corporal, principalmente das mãos e dos olhos, tanto por parte do doente como do são. As recomendações, no caso, têm por fim evitar a transmissão através das mãos contaminadas, com a secreção dos olhos; daí a indicação de que sejam lavadas várias vêzes ao dia, em água corrente, com bastante sabão.

II) Cuidados com os objetos de uso pessoal do doente. Os ensinamentos, neste grupo, têm por fim evitar a transmissão através da bacia e toalha de rosto, da roupa de cama, lenços, etc., pelo que êsses pertences devem ser utilizados exclusivamente pelo doente e depois desinfetados.

III) Emprêgo de água corrente, que alguns autores consideram mesmo a base da profilaxia do tracoma.

A existência de um bom suprimento de água corrente é evidentemente necessária para que sejam executadas medidas de asseio. Quando não há água corrente de torneira, alguns autores recomendam o uso de um barril ou pipa, provido de torneira.

IV) Conselhos no sentido de que os indivíduos se façam examinar e se tratem, quando acometidos pela doença .

Discutiremos, em primeiro lugar ,os conselhos ou ensinamentos que se classificam nos Itens I, II e III.

Conquanto reconheçamos sua justeza e grande alcance, temos fortes motivos para duvidar de seus efeitos, quando divulgados pelos meios atualmente empregados, dadas as características da maioria das famílias acometidas pelo tracoma, no Brasil.

Em primeiro lugar, segundo dados de vários pesquisadores, o tracoma constitui grave problema nas zonas rurais, nas quais é ainda muito elevado o percentual de analfabetos.

Tomemos, por exemplo, o Estado de São Paulo. Segundo Toledo e Azevedo ${ }^{3}$, entre os municípios paulistas de grande incidência, estão: Agudos, Andradina, Bocaina, Borborema, Cafelândia, Cravinhos, Guarantã, Itapuí, Jaú, Lins, Matão, Monte Alto, Orlândia, Osvaldo Cruz, Presidente Alves, Taquaritinga e Tupã.

$\mathrm{Na}$ Tabela 1, damos o número e $\mathrm{o}$ percentual de analfabetos dêsses municípios, segundo o censo de 1950. 


\section{TABELA I}

Numero e percentual de analfabetos, de 5 anos e mais, em alyuns Municipios de São Paulo (julho de 1950)

\begin{tabular}{|c|c|c|c|c|}
\hline \multirow{2}{*}{ M un icípio } & \multirow{2}{*}{ Zona } & \multirow{2}{*}{$\begin{array}{l}\text { População de } 5 \\
\text { anos e mais }\end{array}$} & \multicolumn{2}{|c|}{$A n a l f a b e t o s$} \\
\hline & & & $\mathbf{N}^{\prime 2}$ & $\%$ \\
\hline Agudos & $\begin{array}{l}\text { Cidade } \\
\text { Rural }\end{array}$ & $\begin{array}{l}3.690 \\
9.6 \% 4\end{array}$ & $\begin{array}{r}992 \\
6.161\end{array}$ & $\begin{array}{l}26,9 \\
63,7\end{array}$ \\
\hline Andradina $\quad \ldots \ldots \ldots$ & $\begin{array}{l}\text { Cidade } \\
\text { Rural }\end{array}$ & $\begin{array}{r}7.775 \\
28.716\end{array}$ & $\begin{array}{r}2.502 \\
18.298\end{array}$ & $\begin{array}{l}32,2 \\
63,7\end{array}$ \\
\hline Bocaina $\quad \ldots \ldots \ldots \ldots$ & $\begin{array}{l}\text { Cidale } \\
\text { Rural }\end{array}$ & $\begin{array}{l}2.075 \\
5.375\end{array}$ & $\begin{array}{r}599 \\
5.153\end{array}$ & $\begin{array}{l}28,9 \\
58,7\end{array}$ \\
\hline I3orborema & $\begin{array}{l}\text { Cidade } \\
\text { Rural }\end{array}$ & $\begin{array}{l}1.811 \\
6.551\end{array}$ & $\begin{array}{r}520 \\
3.363\end{array}$ & $\begin{array}{l}28,2 \\
51,3\end{array}$ \\
\hline Cáfelîndia $\quad \cdots \cdots \ldots$ & $\begin{array}{l}\text { Cidade } \\
\text { Rural }\end{array}$ & $\begin{array}{r}4.500 \\
17.260\end{array}$ & $\begin{array}{r}1.176 \\
11.262\end{array}$ & $\begin{array}{l}26,1 \\
65,2\end{array}$ \\
\hline Cravinhos . & $\begin{array}{l}\text { Cidade } \\
\text { Rural }\end{array}$ & $\begin{array}{l}3.528 \\
6.094\end{array}$ & $\begin{array}{l}1.073 \\
4.182\end{array}$ & $\begin{array}{l}30,4 \\
68,6\end{array}$ \\
\hline Guaranta $\quad \ldots \ldots$ & $\begin{array}{l}\text { Cidade } \\
\text { Rural }\end{array}$ & $\begin{array}{r}1.309 \\
10.723\end{array}$ & $\begin{array}{r}451 \\
6.876\end{array}$ & $\begin{array}{l}34,5 \\
64,1\end{array}$ \\
\hline It:ıpuí $\quad \cdots$ & $\begin{array}{l}\text { Cidate } \\
\text { Rural }\end{array}$ & $\begin{array}{l}2.466 \\
8.012\end{array}$ & $\begin{array}{r}894 \\
4.568\end{array}$ & $\begin{array}{l}36,3 \\
57,0\end{array}$ \\
\hline Jaí & $\begin{array}{l}\text { Cidiale } \\
\text { Rurill }\end{array}$ & $\begin{array}{l}16.163 \\
20.855\end{array}$ & $\begin{array}{r}3.918 \\
12.539\end{array}$ & $\begin{array}{l}23,8 \\
60,0\end{array}$ \\
\hline lins $\quad \ldots$ & $\begin{array}{l}\text { Cidade } \\
\text { Rural }\end{array}$ & $\begin{array}{l}20.389 \\
24.309\end{array}$ & $\begin{array}{r}5.308 \\
14.263\end{array}$ & $\begin{array}{l}26,0 \\
58,7\end{array}$ \\
\hline Matão $\ldots$ & $\begin{array}{l}\text { Cidade } \\
\text { Rural }\end{array}$ & $\begin{array}{r}3.108 \\
13.512\end{array}$ & $\begin{array}{r}832 \\
8.457\end{array}$ & $\begin{array}{l}26,8 \\
62,6\end{array}$ \\
\hline Monte Alto & $\begin{array}{l}\text { Cidade } \\
\text { Rural }\end{array}$ & $\begin{array}{l}3.311 \\
9.554\end{array}$ & $\begin{array}{r}886 \\
5.012\end{array}$ & $\begin{array}{l}26,8 \\
52,5\end{array}$ \\
\hline Orlândia . & $\begin{array}{l}\text { Cidarie } \\
\text { Rural }\end{array}$ & $\begin{array}{l}3.415 \\
5.571\end{array}$ & $\begin{array}{r}826 \\
3.254\end{array}$ & $\begin{array}{l}2+, 2 \\
58,4\end{array}$ \\
\hline Osvaldo Cruz. & $\begin{array}{l}\text { Cidade } \\
\text { Rural }\end{array}$ & $\begin{array}{r}5.526 \\
16.255\end{array}$ & $\begin{array}{l}1.716 \\
9.791\end{array}$ & $\begin{array}{l}31,1 \\
60,2\end{array}$ \\
\hline Presidente Ilves ... & $\begin{array}{l}\text { Cidade } \\
\text { Rural }\end{array}$ & $\begin{array}{l}1.38 \% \\
6.8 \% 32\end{array}$ & $\begin{array}{r}387 \\
4.528\end{array}$ & $\begin{array}{l}27,9 \\
66,3\end{array}$ \\
\hline 'vaquaritinga & $\begin{array}{l}\text { Cidade } \\
\text { Rural }\end{array}$ & $\begin{array}{r}6.780 \\
12.193\end{array}$ & $\begin{array}{l}1.456 \\
5.929\end{array}$ & $\begin{array}{l}21,5 \\
48,6\end{array}$ \\
\hline 'นup̃̃ & $\begin{array}{l}\text { Cidade } \\
\text { Rural }\end{array}$ & $\begin{array}{l}15.213 \\
30.498\end{array}$ & $\begin{array}{r}4.613 \\
17.146\end{array}$ & $\begin{array}{l}30,3 \\
56,2\end{array}$ \\
\hline
\end{tabular}

Fonte: Serviço Nacional de Recenseamento. 
Conquanto ainda apreciáveis nas cidades, os percentuais de analfabetismo mostram-se particularmente elevados nas zonas rurais onde, como já dissemos, a incidência do tracoma constitui grave problema.

Ora, como muito bem escreve J. A. Rios ", "para que um indivíduo modifique hábitos de qualquer espécie, é preciso que esteja prèviamente convencido da utilidade dessa mudança".

Uma população com elevada proporção de analfabetos constitui campo difícil de trabalhar no sentido educativo, principalmente porque traz consigo grande carga de hábitos e crenças tradicionais, que vêm de muitas gerações, e que precisam ser substituidos. Os meios de que devemos lançar mão devem ser cuidadosamente escolhidos de acôrdo com o nivel do grupo e executados por pessoas hábeis.

A falta de recursos econômicos, muito comun a êsse grupo, também constitui outro obstáculo para aceitação das medidas recomendadas.

Para confirmar essa impressão, estudamos 10 familias da zona rural do Distrito de Araraquara, no dia 29 de setembro de 1953, das quais 8 representadas por proprietários de pequenos sítios.

Pelo menos 5 das 10 famílias possuiam mobília razoável, máquina de costura, rádio e luz elétrica própria, além de boa casa de moradia.

Em cada uma das dez famílias, havia pelo menos um caso de tracoma, sob tratamento ministrado pelo Serviço Especial de Saúde, de Araraquara.

Antes de visitar as 10 famílias, verificamos que, na cidade de Araraquara, era possível adquirir um barril ou pipa de 100 litros por 50 cruzeiros. Estimamos que a compra e instalação de uma torneira montassem a 10 cruzeiros, o que representaria uma despesa total de 60 cruzeiros, para por em prática uma das recomendações do item III.

As observações que fizemios deram os seguintes resultados:

1) Em 9 famílias, era usada uma bacia comum para lavar o rosto. Apenas 1 das 10 famílias fazia essa limpeza num tanque.

Quase tôdas as famílias informaram que mudavam a água da bacia, depois de utilizada uma vez.

Indagamos de uma das donas de casa, da possibilidade de cada membro da família ter a sua bacia, depois de explicar-lhe o perigo da contaminação. Sua resposta foi que seria muito difícil evitar que uma pessoa se utilizasse da bacia de outra.

2) Nas 10 familias, era utilizada uma toalha comum para enxugar o rosto. 
3) Nas 10 famílias, havia pelo menos duas crianças dormindo na mesma cama. A falta de camas e de espaço era a razão alegada para êsse hábito de colocar as crianças juntas.

4) Em 5 das 10 famílias, as crianças não usavam lenços.

5) Nas 10 familias, havia sabão feito em casa ou comprado, sendo êste último utilizado às vêzes na lavagem do rosto.

6) Apenas 4 das 10 famílias responderam, sem qualquer hesitação, que poderiam gastar 60 cruzeiros, quantia que, como dissemos, seria necessária para adquirir uma pipa com torneira.

A pergunta sôbre a despesa de 60 cruzeiros não se referiu à compra de um barril, mas à de um remédio qualquer. As 6 famílias restantes deciararam que poderiam fazer êsse gasto, se fôsse importante para a saúde.

Verificamos, assim, que em tôdas as famílias, eram praticados pelo menos um dos hábitos considerados maus, do ponto de vista da disseminação do tracoma.

E preciso ressaltar, mais uma vez, que 8 das 10 familias de tracomatosos que investigamos tinham um padrão econômico razoàvelmente bom. Entretanto, o exame do ambiente em que viviam e a conversa que mantivemos com as donas de casa, convenceram-nos de que seria difícil, mas indispensável, modificar-lhes os hábitos de higiene.

Evidentemente, não temos a menor pretensão de generalizar as conclusões a que chegamos, com base na observação das 10 famílias do Distrito de Araraquara. Porém, quando pensamos que essas familias eram representadas por proprietários, embora de pequenos sítios, e apresentavam razoável situação econômica, traduzida, pelo menos em 5 delas, pela existência de rádio, máquina de costura, mobiliário regular, luz elétrica própria e boa casa, não temos dúvida em afirmar que os processos atualmente em uso - quase sempre baseados na palavra escrita - são de precaríssimo valor. Impõe-se, assim, o uso de técnicas modernas, baseadas principalmente na participação popular, com o objetivo de reunir forças e recursos para a solução de um problema que a todos interessa.

Com referência ao item IV, é indispensável, em qualquer programa de profilaxia do tracoma, dar grande realce ao tratamento médico. Devemos, por isso, convencer o indivíduo a se examinar e, no caso de acometimento pela doença, a iniciar o tratamento, nêle perseverando até a cura.

O que seria então recomendável como programa de educação sanitária para uma área com as características da zona rural brasileira, diante de um problema sério, como o tracoma, que exige ação imediata? 
Considerando a urgência que o problema requer, o programa deverá ser dividido em duas etapas. Uma específica, intensiva, e imediata, e outra geral, de longo alcance, contínua e de penetração.

A etapa inicial, visando especificamente o tracoma, consistiria em:

1) Fornecer à população conhecimentos sôbre o tracoma, alertando-a quanto ao perigo da cegueira, invalidez, etc., usando o medo como motivação. A população seria ainda esclarecida quanto às vantagens do exame periódico e do tratamento precoce, imediato e completo, utilizando-se como motivação o desejo de cura.

Neste particular, seriam usados os meios comuns e disponiveis de comunicação com o público, principalmente a palavra falada, através de entrevistas com médicos, enfermeiras, visitadoras e voluntárias que queiram cooperar com a campanha, de palestras, de reuniões com lideres, professoras e outros profissionais.

O médico dispõe de indiscutível prestígio e autoridade junto às familias, as quais, por isso, devem acatar muito melhor os conselhos que ĉle dá; além disso os ensinamentos são feitos num momento psicològicamente propício, pois o médico, ao tratar os indivíduos acometidos de tracoma, está prestando um benefício real à família, numa ocasião de receptividade resultante da motivação criada pela doença. Daí uma das vantagens da visita do médico ao domicílio da família.

Às enfermeiras ou visitadoras cabe, entretanto, reforçar o trabalho iniciado pelo médico, interpretando para as familias os deveres que thes competem.

Os folhetos, cartazes, notícias pelo rádio e imprensa são, como já dissemos, precários, sobretudo em face das características da população a que se destinam. Entretanto, como êles sempre alcançam uma parte dessa população, podemos utilizá-los, mas apenas com o objetivo de agitar o problema.

2) Obter a participação das escolas, as quais podem colaborar no combate ao tracoma de três maneiras: a) facilitando, por todos os modos, o exame dos alunos; b) administrando o remédio prescrito aos alunos doentes durante o periodo de aulas, e c) divulgando ensinamentos sôbre a doença e sua prevenção.

A própria professora, em sua inspeção diária, poderá observar quais as crianças que apresentam sinais suspeitos de tracoma (para isso ela deve ser instruida) e encaminhá-los ao serviço médico, aproveitando a oportunidade para falar sôbre o assunto e pôr em prática, na escola, as medidas preconizadas no item IV. 
A professora, fazendo com que o aluno tome o remédio na sua presença, está prestando uma grande contribuição, pois nos dá certeza de que o doente se medicou.

Não devemos esquecer que as professoras são líderes naturais, que, por isso, muito podem fazer pela saúde da população.

3) Insistir no uso de água corrente para lavagem das mãos e do rosto.

Neste particular, é preciso ter em mente que tratamos, quase sempre, com população de baixo nível econômico. Precisamos, por isso, dar-lhes os recursos materiais necessários.

Se, após estudo dos fatores locais, for indicado o uso de barris, pipas, toneis ou qualquer recipiente, talvez seja possivel adquirí-los através de uma cooperativa, associação beneficente ou serviço de assistência social, e fornecê-los por preço acessível. A venda, ainda que por preço infimo, é sempre preferível à doação, porque a caridade não cria o necessário interêsse.

Lembremos, entretanto, que a simples instalação de um sistema qualquer de fornecimento de água corrente não significa que a familia o utilizará da maneira correta para evitar a disseminação do tracoma.

A experiência com as fossas, que dão mais confôrto às famílias sob todos os aspectos, é muito convincente. Depois de instaladas, tem sido preciso convencer os indivíduos a usá-las.

Por isso, o sucesso de nossa insistência para a lavagem das mãos e do rosto com água corrente vai depender muito da segunda etapa do programa proposto.

Essa segunda etapa, que pode ser iniciada concomitantemente, deve concentrar-se na participação popular, procurando-se atrair os lideres da região para uma ação conjunta, em benefício comum.

Essa etapa não tem limite de tempo. Sabemos, fora de qualquer dúvida, que a incorporação de novos hábitos, mudança de atitudes e de comportamento de uma dada população, enfim, qualquer modificação no seu modo de viver, requer trabalho habilidoso e paciente.

Não será a simples distribuição de folhetos que operará o milagre.

As práticas modernas de organização de grupos ou de comunidades, devem ser hábil e oportunamente usadas e, para isso, há necessidade absoluta de que o pessoal do serviço de saúde tenha um treinamento especializado, para bem conduzir um trabalho de tal natureza.

Êsse trabalho envolve conhecimentos que o pessoal do serviço de saúde habitualmente não possui, como, por exemplo, sociologia e antropologiá rurais, psicologia educacional, individual e de grupo, organização de comunidade, técnicas de reunião, de entrevistas, etc. Por êsse motivo, é contra- 
indicado iniciar um programa de organização de comunidade sem pessoal preparado para tarefa tão complexa.

Além disso, um programa cujo objetivo é a mudança de atitude ou de comportamento tem de ser planejado com a intenção de atender as necessidades e os interêsses da população, para o que devemos usar métodos que se ajustem ao seu modo de vida.

Um programa como o que delineamos certamente encontrará dificuldades, mas acreditamos que, atualmente, seja o mais indicado, se quisermos atingir os objetivos principais da educação sanitária que é o de levar a população a agir na parte que lhe compete para a melhoria da saúde física, mental e social.

\section{CONCLUSÕES}

1. O programa de educação sanitária, cujo papel na profilaxia do tracoma é muito importante, deve compreender duas etapas: uma inicial, intensiva e imediata, dirigida especificamente contra o tracoma, e outra geral, contínua e de longo alcance.

2. A etapa inicial deve consistir bàsicamente, em: a) dar a população conhecimentos sôbre a doença; b) convencer as famílias a se submeterem a exame (e a tratamento, caso necessário), e c) obter a participação das escolas.

3. A segunda etapa deve consistir no emprêgo das modernas técnicas de educação que visem obter a participação popular no solucionamento de seus problemas.Entre elas, sobressai a da organização de grupos ou de comunidades.

4. Tendo em vista a complexidade da segunda etapa, que se utiliza de técnicas de valor comprovado quanto à mudança de atitude ou de comportamento, é recomendável que ela só seja iniciada se for possível contar com pessoal especializado.

\section{RESUMO}

1 -- Os autores acham que um programa de educação sanitária, nos trabalhos de combate ao tracoma, deve compreender duas etapas: a primeira, imediata e intensiva, dirigida especificamente, contra o tracoma, e a segunda, geral, contínua e de longo alcance. 
2 - A etapa inicial deve consistir, bàsicamente, em:

a) ministrar à população conhecimentos sôbre a doença;

b) convencer as famílias a se submeterem a exame e a tratamento, se necessário;

c) obter a participação ativa das escolas.

3 - Na segunda etapa devem ser usadas as modernas técnicas de educação, visando obter a participação popular no solucionamento de seus problemas, destacando-se, dentre elas, a organização de grupos e de comunidades.

4 - Considerando a complexidade da segunda etapa, que se utiliza de técnicas de comprovado valor na mudança de hábitos ou de comportamento, é recomendável que ela só seja iniciada se for possível contar com pessoal especializado.

\section{SUMMARY}

1 - Any health education campaign against trachoma should include two phases. The first should be immediate, intensive and specifically directed against trachoma; the second should be of long-term duration and general in character.

2 - The initial phase should basically consist of:

a) teaching the people the important aspects of the disease;

b) convincing the families to apply for medical examination and treatment, if necessary;

c) securing close cooperation of schools.

3 - In the second phase all the modern educational techniques which aim at obtaining active participation of the people in the solution of its own problems should be used. Among these, group and community organization is particularly useful.

4 - Due to the complexity of the second phase, it is recommended that it be initiated only if one can depend on specialized personnel. 


\section{BIBLIOGRAFIA}

1. Barreto, J. de B.: Compêndio de Higiene. Rio de Janeiro, Editora Guanabara, 1951.

2. Rios, J. A.: Informar e convencer. Bol. de SESP, n. 35, jun'53.

3. Toledo, S. de A. \& Azevedo, P. A.: Carta geográfica da incidência do tracoma no Estado de São Paulo. Arq. Hig. Saúde Púb. 17:54, 559-565, 1952.

4. World Health Organization. Expert Committee on Trachoma: First report. Geneva, 1952. (Technical report series, n. 59). 